\section{Somatic Stability in the Newly Born}

A Ciba Foundation Symposium edited by G. E. W. WOLSTENHOLME, O.B.E., M.A., M.B., M.R.C.P., and Maeva O'ConNor, B.A. Pp. xii +393 , illustrated. London: J. \& A. Churchill. I96r. 5os.

This is an excellent symposium.

The overall theme is that of homoeostasis in the perinatal period. Papers and discussions range over renal, cardiovascular, endocrine and nervous system aspects, whilst metabolism in relation to the intrauterine environment, carbohydrates and the role of the liver and body temperature regulation are considered. The human, the rat, the pig, the rabbit are among the new-born animals described and to the special problem of the Pulmonary Syndrome in New-born Foals is devoted a single paper. Almost every paper has something of value to give to the pædiatrician, physiologist, biochemist, veterinarian and indeed to any experimental worker in the human or animal neonatal field. The clinician can receive help in his problems from Usher's views on the Respiratory Distress Syndrome, Villee on Establishment of Enzyme Systems, Richter on the Nervous System, Midgeon on Endocrine Function, Dawes on Oxygen Consumption and Hypoxia, Widdowson on Metabolic Effects of Fasting and Food, James on Asphyxia, Vesterdal on Kidney Function and Kerpel-Fronius on the Clinical Aspects of Stability.

The research worker will surely read with interest Hill's treatment of the Physics and Physiology of the development of Homoeothermy, Holm et. al on Aspects of Homoeothermy in Rats, Mount on Metabolic rate and Body Temperature, and Zetterström on the Liver and Carbohydrate Metabolism (not excluding the papers enumerated for their clinical value).

All the papers give evidence of the meticulous nature of the investigations and the high standard of the research carried out. The discussions recorded must stimulate many new thoughts and new ideas.

How pleasant it is to see so excellent a publication in print in the same year as the symposium occurred.

\section{Artificial Feeding in Early Infancy}

ANDREW BOGDAN, M.D., M.R.C.P.E., D.C.H. Tutorial Systems Publications Pædiatric Series. Pp. 24. 1961. 3s. $6 d$.

This booklet can be recommended to medical students who are at the beginning of their pædiatric studies. It sets out clearly some of the main points which must be understood before such a wide subject as infant feeding is studied in detail. Like all 'potted' subjects a danger lies in regarding these notes as rules, and emphasis must be laid on the author's comment that infants are individuals, and must be treated as such in all matters pertaining to their welfare, including feeding.

The possession of the booklet, giving an outline of infant feeding, should encourage the student to seek practical experience, this being the only way in which advice in the early days of feeding can be given with assurance.

The author may be pardoned for certain lapses in the description of preparing milk foods, for a good method is only discovered by trial and error.
With the present trend of the early introduction mixed feeding this subject could be included with promit to the student.

The booklet is a useful aid to the elementary stud of infant feeding, but its value is naturally limited.

\section{Chemical Pathology of the Nervous System}

Proceedings of the Third International Neurds chemical Symposium, Strasbourg, 1958. Edite by JoRd FolChi-PI. Pp. xix $+720,142$ tables 221 figures, index, references. Oxford, Londo? New York and Paris: Pergamon Press. 196. f.7.

Neurochemistry is an almost popular speciality, so it hardly surprising that over 130 scientists from all parts of the world gathered at Strasbourg in 1958 to discuss mare aspects of the chemical pathology of the nervous systent. Professor Jordi Folchi-Pi has performed a remarkable service to all those interested in neurology and psychiatr $\bar{y}$, for he has edited the proceedings of that meeting and produced a volume of about 700 pages. The papes given and recorded concern the chemistry of metabolre disorders, especially those of inborn error and of nutritional origin, the chemical pathology of copperan the chemistry of demyelination. There are sectiong on electrolytes and on convulsive states. Rather surprisin more than a third of the volume is devoted to the possible role of biochemical factors in mental diseases.

Many of these topics are introduced by a paper of review nature, which is then followed by original articles. It is impossible to select individual authors for specio comment, only to say that, as is usual, some are bette than others. It would not be out of place to say that the final paper by Dr. S. S. Kety should be read and his critical approach to his own and other scientists' research copied by all.

This volume is recommended to all interested in this field and is a faithful record of a very memorable meeting.

\section{Cardiac Arrhythmias: A Guide for the Genera} Practitioner

Brendan PhibBs, M.D. Pp. 1 28, illustrated. S龟 Louis: C. V. Mosby. London: Henry Kimpto 196r. 56s.

Few books have been published that deal solely with the cardiac arrhythmias and are directed at the grea bulk of medical practitioners. The subject is usual dealt with in books on electrocardiography and is sand wiched between complicated vector drawings of impulses going through blocks of muscle and the discussion of hypertrophy and ischæmia. Dr. Phibbs's boof however, requires no previous knowledge of electrocardiography and explains only enough for the reader to be able to recognize atrial and ventricular complexes. 0

For the general practitioner, the surgeon, the studen and the anæsthetist the book sets out the classical facts of arrhythmias in a concise, tabulated form. It can be read in an hour or two and the mind is not diverted by theorizing on causation or modes of production. references are given and for the postgraduate in interna 
medicine or the physician this book would not go far enough.

Many illustrative electrocardiographic tracings are given and some useful notes on the clinical aspects of the disorders. Although the practitioner is encouraged to diagnose the arrhythmias at the bedside, he is not expected to hear atrial sounds, count venous waves in the neck, or be deluded into thinking that he should always be able to distinguish atrial fibrillation from multiple ectopic beats without an electrocardiograph.

Practical notes on treatment are given with each section. However, one views with disquiet the type of medical practitioner for whom this book is designed, using many of the reversion techniques, when without a good deal of experience. The American general practitioner may have more opportunity for using such drugs as quinidine and procainamide, but his British counterpart sees little of his patient's treatment in hospital.

Thus to the practitioner who wishes to know more of arrhythmias without becoming involved in electrocardiography this book will appeal.

\section{The Anatomy of the Eye and Orbit}

Eugene WolfF. Fifth edition. Revised by R. J. LAST, M.B., B.S., F.R.C.S.ENG. 438 illustrations (54 coloured). Pp. viii +500 , London: H. K. Lewis. $£ 44$ s.

This book was first published in 1933 and following the death of Eugene Wolff the fifth edition has been revised by Professor R. J. Last. It presents a clear account of the macroscopic and microscopic structure, development and comparative anatomy of the visual apparatus. With advances in technique and the introduction of the electron microscope anatomy is a growing subject.

There are some omissions in the book, such as recent work on the oculo-motor nucleus and the blood supply of the optic nerve head.

The book is well produced and richly illustrated. Most of the author's original black and white drawings have been retained.

Professor Last has preserved the spirit and pattern of the original work and it can be highly recommended to students of ophthalmology and to those interested in the anatomy of the visual apparatus.

\section{Essentials of Neurology}

John N. Walton, M.D., M.R.C.P. Pp. xvii +422 , illustrated. London: Pitman Medical Publishing Co. 196r. 30 s.

The need for a brief text book of neurology has been felt for some time but it is not certain, however, that the need has been completely fulfilled. Dr. Walton's book is intended for undergraduate and postgraduate students, and for practitioners. Compression has been achieved partly by limiting the scope of the work, which is written from the standpoint of the bedside neurologist. Accounts of normal and disordered physiology, and of pathology, have largely been omitted and are only mentioned when 'absolutely necessary for an understanding of clinical principles '. Nevertheless, the book is, in general, remarkably comprehensive. An exception is the chapter on psychiatric disorders which is so sketchily written that its inclusion seems hardly profitable. The reviewer also objects, on semantic grounds, to its entitlement as 'Disorders of the Mind'.

With regard to the general plan of the book, Dr. Walton begins by considering some useful general principles, and follows this by chapters on the investigation of the neurological patient. The remainder of the first half of the book consists of an analysis of the principal symptoms and signs produced by diseases of the nervous system. In the second half, he presents a description of individual diseases and syndromes and concludes with a chapter, perhaps a little too abbreviated, on treatment in neurology. The style is fluent, making the work surprisingly readable in view of the condensation of material that has been achieved.

Dr. Walton's 'Essentials of Neurology' represents a useful addition to the teaching of neurology.

Advances in Biology of Skin: Vol. I-Cutaneous Innervation

Edited by William Montagna. Pp. xii +203 , with 118 illustrations. Oxford, London, New York, Paris: Pergamon Press. 1960. 63 s.

This publication represents the proceedings of the Brown University Symposium on the Biology of the Skin held in 1959. Recent years have yielded innervation as newer histological and electrophysiological techniques have been applied. The participants in this symposium include several of those who have contributed to these advances.

Accounts of the histological aspects of cutaneous innervation have been provided by Malcolm Miller and his associates, R. K. Winkelmann and William Montagna. The high quality of the photographic plates illustrating these articles is to be commended. The changes in knowledge of cutaneous neurohistology that have accrued over the past two decades have given rise to problems concerning the mechanism of cutaneous sensibility. Fxperiments relating to a possible solution are described by Graham Weddell. There are also two chapters by G. H. Bishop on the relation of nerve fibre size to modality of sensation and to the organization of the central paths of the cutaneous afferents, which are an interesting synthesis of physiological and anatomical studies. Other articles are on autonomic innervation and on the mechanism of itch.

Although much of the material included has been published elsewhere, this book provides a useful compilation of recent work in this important field.

\section{The Practical Management of Head Injuries}

John M. PotTer, M.A., M.B., B.Chir.(CANTAB.), F.R.c.s. Pp. xii +84 , illustrated. London: LloydLuke (Medical Books). 196r. I2s.

This short account of the management of head injuries begins by considering the examination and assessment of the patient in the casualty department and follows with an account of care in the ward. A chapter is devoted to the treatment of complications and finally one to the important question of rehabilitation after head injuries. It is lucidly written in an informal and engaging style. The author has undoubtedly succeeded in providing a book that, to quote from the preface, is 'a practical guide ... not designed to help those who merely wish to pass surgical examinations'.

\section{A Manual of Psychiatry}

K. R. Stallworthy, M.B., Ch.B., Diploma Psychological Medicine. Fifth edition. Pp. 386. Christchurch, New Zealand: N. M. Peryer. 1961. 305.

Both Dr. Stallworthy and the writer of the foreword suggest that this 'Manual of Psychiatry' is suitable for students, general practitioners and nurses. This is not so. It might possibly suffice to acquaint a long-established general practitioner whose psychiatric education had been neglected as an undergraduate with the 